\title{
TURISMO ACESSÍVEL EM GUIMARÃES. OPORTUNIDADE E DESAFIO PARA UMA CIDADE INCLUSIVA
}

\author{
M. J. Caldeira ${ }^{1}$, N. Silva ${ }^{2}$, F. Nunes ${ }^{1}$ \\ Departamento de Geografia da Universidade do Minho, CEGOT-UMinho, Campus de Azurém, \\ boavida@geografia.uminho.pt
}

Submetido 27/10/2016 - Aceito 28/07/2017

DOI: $10.15628 /$ holos.2017.5274

RESUMO: A equidade social, o turismo para todos e a cidade inclusiva e justa são preocupações cada vez mais presentes nas sociedades contemporâneas, em especial na ação dos planeadores e das entidades públicas com responsabilidades em matéria de gestão urbanística. Contudo, apesar do desenvolvimento de planos onde este tipo de preocupações começa a estar presente, e da consciencialização da sociedade para os problemas da acessibilidade para os cidadãos com necessidades especiais, as cidades de hoje, efetivamente, ainda não se encontram acessíveis a todos. Neste contexto e face a este desafio a promoção do turismo acessível é um desígnio que deve estar subjacente a uma oferta turística atual e inclusiva. Pelo que neste estudo se procura analisar a adequabilidade da região Norte de Portugal e, mais concretamente, da cidade de
Guimarães, a práticas turísticas desenvolvidas por cidadãos com deficiência física.

O centro histórico da cidade de Guimarães, classificado pela UNESCO em 2001 como Património da Humanidade é um importante destino turístico no Norte de Portugal. Neste artigo analisa-se a adequação e as condicionantes que um percurso turístico recomendado para o Centro Histórico de Guimarães oferece a um turista com mobilidade reduzida. A finalidade é despertar as autoridades locais para a necessidade de adequar a oferta turística e a cidade a todos os públicos, bem como disponibilizar informação adequada a turistas/excursionistas com mobilidade condicionada por forma a proporcionar um melhor planeamento da sua visita. Deste modo pretende-se contribuir para que a Cidade de Guimarães se possa afirmar como uma cidade progressivamente mais inclusiva.

PALAVRAS-CHAVE: Mobilidade, Acessibilidade, Turismo Acessível, Planeamento Urbano, Guimarães

\section{Accessible tourism in Guimarães. Opportunity and challenge for an inclusive city.}

\begin{abstract}
Social equality, tourism for all and inclusive and fair city are increasingly present in the concerns of contemporary societies, especially in the action of planners and public entities with responsibilities in urban management. However, despite the development of plans where this type of concern begins to be present and the awareness of society to the problems of accessibility for people with special needs, the cities are not yet accessible to all. In this context, the need of developing an accessible tourism is a purpose that should sustain any strategy to promote a more inclusive society. So, this study analysis the progress of North of Portugal, and specifically of Guimarães city, in what concerns to the accessible tourism.
\end{abstract}

The Historic Center of Guimarães, classified by UNESCO in 2001 as World Heritage, is a significant tourist destination in northern Portugal. The aims of this article is to analyze the adequacy and conditions that the tourist route, recommended for the Historic Center of Guimarães, offers to a tourist with limited mobility. The purpose is to raise local authorities to the need to adapt the tourism and the city to all public and provide appropriate information to tourists / excursionists with disabilities, in order to provide a better planning of the visit. Thereby we intended to contribute to a diagnostic of accessibility conditions of the City Center of Guimarães and propose some measures towards a city progressively more inclusive.

KEYWORDS: Mobility, Accessibility, Accessible Tourism, Urban Planning, Guimarães 


\section{INTRODUÇÃO}

De acordo com dados da Organização Mundial de Saúde, estima-se que em 2012 cerca de $15 \%$ da população mundial (ou seja, um pouco de mais de mil milhões de pessoas) tenha algum tipo deficiência, e estima-se que, em 2050, este número aumente para cerca de 1,2 mil milhões de habitantes (OMS, 2011). Em Portugal, em 2011 um pouco mais de 2 milhões de residentes tinham mais de 65 anos, cerca 1 milhão de pessoas possuía alguma deficiência, cerca de 500 mil crianças tinham menos de 5 anos e alguns milhares de pessoas tinham problemas de mobilidade (INE, 2011).

Perante este contexto a criação de melhores condições de mobilidade e acessibilidade para todos deve constituir um desígnio na ação dos planeadores e das entidades públicas com responsabilidades em matéria de gestão urbanística, por forma a eliminar distinções na possibilidade de utilização plena de todo e qualquer território. Como afirma Carlos Ramos, Presidente do Laboratório de Engenharia Civil "a promoção da acessibilidade constitui um elemento fundamental para a qualidade de vida de todos os cidadãos, sendo sentida de forma mais acentuada por aqueles que têm limitações de mobilidade. A acessibilidade tem vantagens para todos os cidadãos, para a comunidade e para o Estado visto que permite o exercício pleno de cidadania e participação ativa nos diversos domínios da sociedade, assegura a todos, situações de igualdade de oportunidades" (SNRIPD, 2007:13).

Apesar de uma maior consciencialização da sociedade e das autoridades para os problemas da acessibilidade dos cidadãos com necessidades especiais, as cidades de hoje efetivamente ainda não se encontram acessíveis a todos. Em 2003, um estudo da DECO divulgou que em Portugal, devido à falta de acessibilidade, cerca de metade das pessoas com deficiência motora desistiu de ir ao cinema e $40 \%$ de frequentar museus e bibliotecas (DECO, 2011).

Numa sociedade que se pretende coesa, justa e equitativa as questões da mobilidade e acessibilidade para todos não podem ser ignoradas no planeamento e ordenamento do território e particularmente, no que diz respeito ao planeamento do espaço urbano. Sendo necessário dotar os edifícios e as vias públicas de condições de acessibilidade universal.

A maioria das autoridades com responsabilidades na gestão das cidades, na atualidade, estão atentas à necessidade de pensar e planear o território para todos e para utilizadores distintos, sejam eles residentes, visitantes, turistas, trabalhadores, crianças, jovens, adultos, idosos, assim como para quem não tem qualquer problema de mobilidade ou para os de mobilidade reduzida.

É neste contexto, em que cada vez mais as cidades têm que ser pensadas, planeadas e geridas considerando os diferentes públicos que as utilizam, que o turismo se tem afirmado como um dos setores económicos mais dinâmicos e importantes para os territórios. Os turistas ou excursionistas são utilizadores frequentes dos espaços urbanos e como tal é necessário pensar na adequabilidade das cidades à receção de qualquer tipo de turista. Nesta perspetiva tem-se desenvolvido um nicho de turismo designado por turismo acessível que pretende analisar, alertar e divulgar os espaços turísticos adequados e adaptados para receber turistas que revelam alguma incapacidade física. Para reforçar a importância deste nicho de mercado, Buhalis e Costa (2005) referem que a procura pelo produto acessível, na Europa, era de 125 milhões de pessoas com mobilidade reduzida, 2 milhões de pessoas idosas, 1 milhão de pessoas deficientes, 500 mil crianças com menos de 5 anos e outros milhares de pessoas lesionadas (Teles, 2014). 
Face a este desafio, este artigo pretende analisar a adequabilidade da oferta hoteleira do Norte de Portugal ao turismo acessível, bem como avaliar um percurso turístico no centro histórico da cidade de Guimarães no que concerne à sua acessibilidade para turistas com mobilidade reduzida. Para tal foi efetuada uma análise à oferta hoteleira, às condições físicas do percurso e à adequação de equipamentos, monumentos, comércio e serviços a este tipo de turistas. Testa-se assim a possibilidade de se criarem ferramentas que forneçam um conjunto de informações fundamentais para os turistas com mobilidade condicionada poderem planear facilmente e com antecedência uma visita ao centro histórico de Guimarães. Simultaneamente este trabalho pretende alertar as autoridades locais e os agentes turísticos para alguns problemas e soluções que podem ser adotados localmente, em prol de práticas de planeamento mais equitativas, responsáveis e socialmente mais justas.

A metodologia seguida nesta pesquisa envolveu procedimentos distintos. Para além de pesquisa bibliográfica sobre as questões conceptuais, procedeu-se a uma breve contextualização quantitativa sobre a oferta de alojamentos turísticos adaptados a pessoas com mobilidade reduzida na região Norte, baseada na informação presente no website de reservas de alojamento turístico 'www.booking.com'. Para o município de Guimarães procedeu-se à validação da informação através de contatos telefónicos. A sistematização e o tratamento da informação recolhida permitiu o cálculo dos quocientes de localização por forma a permitir distinguir os concelhos que se destacam ao nível da oferta de alojamentos com quartos adaptados a turistas com mobilidade reduzida, na região Norte de Portugal.

Numa segunda fase foi selecionado o percurso turístico para a visita dos principais atrativos do centro histórico de Guimarães, recomendado pelo Posto de Turismo local. Após a seleção do percurso foi efetuada uma avaliação dos espaços públicos exteriores, recolhendo informação sobre parâmetros diversos de caracterização do espaço público, como a existência de barreiras arquitetónicas, dimensão dos passeios, tipo de pavimento, existência de passadeiras rebaixadas, bem como quanto ao tipo de circulação nas vias. Foi calculado ainda o declive da via associado ao percurso selecionado, sendo que as classes adotadas para avaliar a adequação do declive à circulação de pessoas com mobilidade reduzidas são as utilizadas no Plano de Acessibilidade Pedonal de Lisboa (CML, 2013). Numa segunda etapa procedeu-se à avaliação do acesso aos espaços interiores (públicos e semi-públicos), tendo por base um inventário dos monumentos, equipamentos, comércio e serviços existentes ao longo do percurso selecionado e potencialmente utilizáveis por turistas, aferindo a sua acessibilidade e adaptação a pessoas com mobilidade reduzida.

A avaliação não se restringiu à identificação das características de adequação dos espaços exteriores e interiores a cidadãos com mobilidade reduzida, pois esta foi complementada com registos obtidos com um teste in-loco, que consistiu na experiência de percorrer o percurso selecionado acompanhando as dificuldades sentidas por uma pessoa com mobilidade reduzida, permitindo assim atingir uma maior fiabilidade na avaliação do grau de acessibilidade do mesmo.

\section{Mobilidade, ACESsibilidade para todos e planeamento uRbano}

Os conceitos de "mobilidade" e de "acessibilidade" são, por vezes, erradamente utilizados como sinónimos. O conceito de "mobilidade" corresponde ao movimento de indivíduos, de mercadorias e de informação, que deve ser medido em número de viagens, em distâncias e em velocidades (Litman, 2007). Segundo Metz (2000) a mobilidade pode ser entendida como "sinónimo de deslocação embora também possa ser utilizado como sinónimo de limitação física" 
(in: Ribeiro, 2014:33)

No que respeita à mobilidade pedonal um dos maiores problemas relaciona-se com a existência de barreiras ou obstáculos que dificultam ou impossibilitam as deslocações a pé. As barreiras urbanísticas, as ruturas de continuidade dos percursos, a instabilidade na colocação do mobiliário urbano, a degradação do piso, os estacionamentos abusivos são alguns dos exemplos de problemas que condicionam a mobilidade dos pedestres.

De acordo com a Agência Portuguesa do Ambiente - APA (2010), é possível identificar dois tipos de barreiras para este tipo de mobilidade, as físicas e as outras barreiras (ambientais, culturais, institucionais, etc.). As barreiras físicas consistem sobretudo em obstáculos que, de alguma forma, irão congestionar fisicamente os movimentos, tais como a ausência de infraestruturas adequadas (pavimento degradado, largura reduzida, ausência de passadeiras), a existência de barreiras arquitetónicas (escadas que dificultam ou impedem a acessibilidade dos peões, a existência de placas, paragens de autocarros, etc.) ou a ausência de uma rede integrada de percursos qualificados. Já nos outros tipos de barreiras podemos englobar, por exemplo, o estacionamento ilegal ou a falta de planeamento urbano no que toca a meios de transporte público amigos do ambiente. Deste modo o planeamento urbano deve ser particularmente sensível a estas barreiras diversas, para que os percursos pedonais respondam a um conjunto de critérios que emanam do conceito de "walkability", possibilitando um ambiente urbano com maior qualidade e mais inclusivo.

A definição de "acessibilidade" é mais complexa e pode ser entendida como característica/vantagem de um lugar em virtude de se superar um determinado obstáculo que pode ser medido através do tempo e da distância (Ingram, 1971). No entanto o conceito nem sempre é utilizado para expressar a capacidade de uma localização ser alcançada, o que se relaciona com a estrutura e funcionamento do sistema de transportes; pois existem também os autores que utilizam o conceito para expressar a liberdade/facilidade com que os indivíduos utilizam as diferentes atividades e equipamentos, beneficiando das oportunidades que lhes estão associadas, nomeadamente em matéria de desenvolvimento económico e qualidade de vida (Guitérrez et al., 2007, in Ribeiro, 2014). Diversas autoridades, como Organização Mundial de Saúde ou a Comissão Europeia, têm, nos últimos anos, dedicado particular atenção a esta temática. A nível internacional, em 1990, é publicado pelo Comité Coordenador para a Promoção da Acessibilidade da Holanda o Manual Europeu de Acessibilidade, seis anos mais tarde surge na Comunidade Europeia, o Conceito Europeu de Acessibilidade (ECA), estas duas publicações foram marcos importantes no debate do conceito de acessibilidade.

O Conceito Europeu de Acessibilidade considera a acessibilidade como um atributo essencial do meio edificado sustentado e centrado na pessoa, tendo como alvo todas as pessoas de todas as idades, e capacidades (EUCAN, 2003). Este conceito assenta em três princípios de design universal, nomeadamente: i) a disponibilização de meios físicos adequados, seguros, usufruídos por todos, incluindo as pessoas com deficiência; ii) a rejeição da divisão que se faz de pessoas sem e com deficiência; iii) a aceitação do design universal incluir disposições complementares sempre que necessário (EUCAN, 2003). A par da apresentação destes princípios foi desenvolvido o manual de Desenho Universal (Design for All) que visa a conceção de objetos, equipamentos e estruturas do meio físico destinados a ser utilizados pela generalidade das pessoas, sem recurso a projetos adaptados ou especializados" (Anacleto, 2014).

1 - De uma forma sucinta, pode ser entendido como " uma medida da forma urbana, que avalia a qualidade e 
A relevância desta problemática implicou que, em 2010, a União Europeia criasse o prémio "Access City Award", para cidades da UE com mais de 50.000 habitantes. Esta distinção pretende reconhecer e celebrar os esforços desenvolvidos pelas cidades para garantir a acessibilidade para todos, funcionando como incentivo e difusão de boas práticas, colocados em exposição para avaliação e possível adoção por outras cidades europeias.

Neste trabalho em particular vamos assumir os dois conceitos, a mobilidade encarada no sentido da deslocação dos indivíduos em meio urbano, associado à acessibilidade encarada como a capacidade do meio (espaço, edifício ou serviço) conseguir proporcionar a todos os cidadãos (independentemente do seu grau de capacidade) uma igual oportunidade de uso, de forma direta, imediata, permanente e o mais autónoma possível (CML, 2013).

Contudo, novos padrões de mobilidade e acessibilidade não podem ser ignorados no planeamento e desenho urbano a menos que se pretenda perpetuar e aumentar uma possível fragmentação no uso e apropriação do espaço urbano. Assim é necessário desenhar e projetar edifícios adequados à utilização de todos e planear percursos pedonais acessíveis e com continuidade, desobstruídos de barreiras físicas. Para isso, a construção no meio físico deve ter em consideração as diferentes necessidades dos utilizadores, em particular das pessoas cuja mobilidade é condicionada por diferentes razões e graus, por forma a permitir, um território pensado para todos (IMTT, 2003).

\section{TURISMO ACESSÍVEL}

O primeiro conceito de "turismo para todos" surge em 1980, pela Organização Mundial do Turismo na Conferência de Manila, que reconheceu o turismo como um direito fundamental e um veículo chave para o desenvolvimento humano, recomendando aos Estados-membro a regulamentação dos serviços turísticos e sublinhando os aspetos mais importantes da acessibilidade ao turismo. É nesta conferência que surge pela primeira vez a associação da acessibilidade ao turismo (Pérez e Velasco, 2003).

Em 1999, os membros da Organização Mundial do Turismo (OMT) reúnem-se numa Assembleia Geral que regulou o "Código Mundial de Ética do Turismo" e, no artigo 2oㅡ na alínea 2 desta declaração salienta-se que "as atividades turísticas devem respeitar a igualdade entre homens e mulheres; devem tender a promover os direitos do homem e, especialmente, os particulares direitos dos grupos mais vulneráveis, nomeadamente as crianças, os idosos ou deficientes, as minorias étnicas e os povos autóctones" (OMT, 1999). É na sequência desta Assembleia Geral da OMT que a mobilidade e a acessibilidade para todos ganha especial destaque na atividade turística, uma vez que se afirma que o direito de viajar e de aceder livremente ao património, à cultura e ao lazer não deve ser impedido pela existência de barreiras arquitetónicas (artigo 70 do Código de Ética Mundial para o Turismo) (SNRIPD, 2007).

Uma das definições mais simples de turismo acessível, é proporcionada pela Visit Britain, Agência nacional de turismo, responsável pelo marketing turístico do Reino Unido, e que o apresenta como "a facilidade com que todos podem usufruir de experiências turísticas" (INI, 2010: 21). Mas que numa forma mais elaborada e operativa pode ser definido como "uma forma de turismo que, através de processos de colaboração entre as diversas partes envolvidas, apresenta uma oferta de produtos, serviços e ambientes baseados no conceito do Design Universal - de forma a eliminar ou mitigar todos os tipos de barreiras físicas, humanas ou de informação -, permitindo às pessoas que apresentem quaisquer espécies de necessidades 
especiais, assim como aos seus acompanhantes, a prática da atividade turística de uma forma equitativa, digna e segura, sempre orientada para a máxima independência" (Carvalho, 2015: 82). Ou seja, o conceito de turismo acessível procura garantir um conjunto de serviços e de infraestruturas que respeitem o desenho universal, tornando-os capazes de receber todos os indivíduos independentemente da sua condição física. Implica disponibilizar recursos e estratégias de forma a atender um público diferenciado, que exigirá uma atenção particular em aspetos específicos de alojamento, restauração, atividades de animação, transportes, espaços públicos, equipamentos e procedimentos operacionais.

Deste modo, o turismo acessível implica uma aposta nas condições de acessibilidade das diversas componentes de que é feito o destino: incluindo o alojamento e os locais a visitar (restaurantes, museus, parques, praias, etc.); os serviços aí disponíveis; as infraestruturas que suportam a deslocação até ao destino e no destino (estações de comboio, parques de estacionamento, metro, etc.); bem como nos meios através dos quais é disponibilizada informação sobre o destino ao turista que pretende programar a visita (atrações turísticas existentes e condições de acessibilidade).

Estas são preocupações que têm que estar cada vez mais presentes se se pretende apostar no segmento do turismo de qualidade e acessível para todos, até porque, com base num estudo realizado pelo Projeto OSSATE, se estimava que em 2005 a dimensão do mercado turístico no segmento da acessibilidade seria de cerca de 127,5 milhões de europeus (número calculado com base em 7 segmentos de deficiência e na população idosa), valor que representava mais de $27 \%$ da população europeia (Buhalis et al., 2005). Este estudo revelou ainda que os europeus com deficiência gozavam em média mais do que um período de férias por ano, e viajariam ainda mais se houvesse mais destinos acessíveis e mais informação disponível sobre a sua acessibilidade (INI, 2010).

\section{TURISMO ACESSível EM GUIMARÃES}

Na sua componente empírica este estudo tem como objeto de análise as condições de mobilidade e acessibilidade que o Centro Histórico de Guimarães apresenta para um turista com mobilidade reduzida. Contudo, como a cidade de Guimarães se insere numa Região que nos últimos anos tem vindo a afirmar-se como um destino turístico relevante e porque a experiência turística se inicia, frequentemente, pela procura e marcação de alojamento fora do concelho, procura-se perceber a situação no que concerne à oferta de alojamento turístico com condições para acolher turistas com mobilidade reduzida, na região Norte de Portugal.

Para esta análise utilizámos como fonte de informação o website de marcações online 'www.booking.com', com o intuito de perceber quais os municípios que na região Norte apresentam melhores resultados ao nível da oferta de alojamentos turísticos com quartos adaptados a indivíduos com mobilidade reduzida (Figura 1 ).

Através desta pesquisa foi possível perceber que, no seu conjunto, a Região Norte de Portugal $^{2}$ dispõe de 1865 alojamentos turísticos registados neste portal de pesquisa, sendo que apenas $343(18,4 \%)$ possuem pelo menos um quarto adaptado para pessoas com deficiência motora.

\footnotetext{
${ }^{2}$ - A região Norte é composta por 86 municípios.
} 


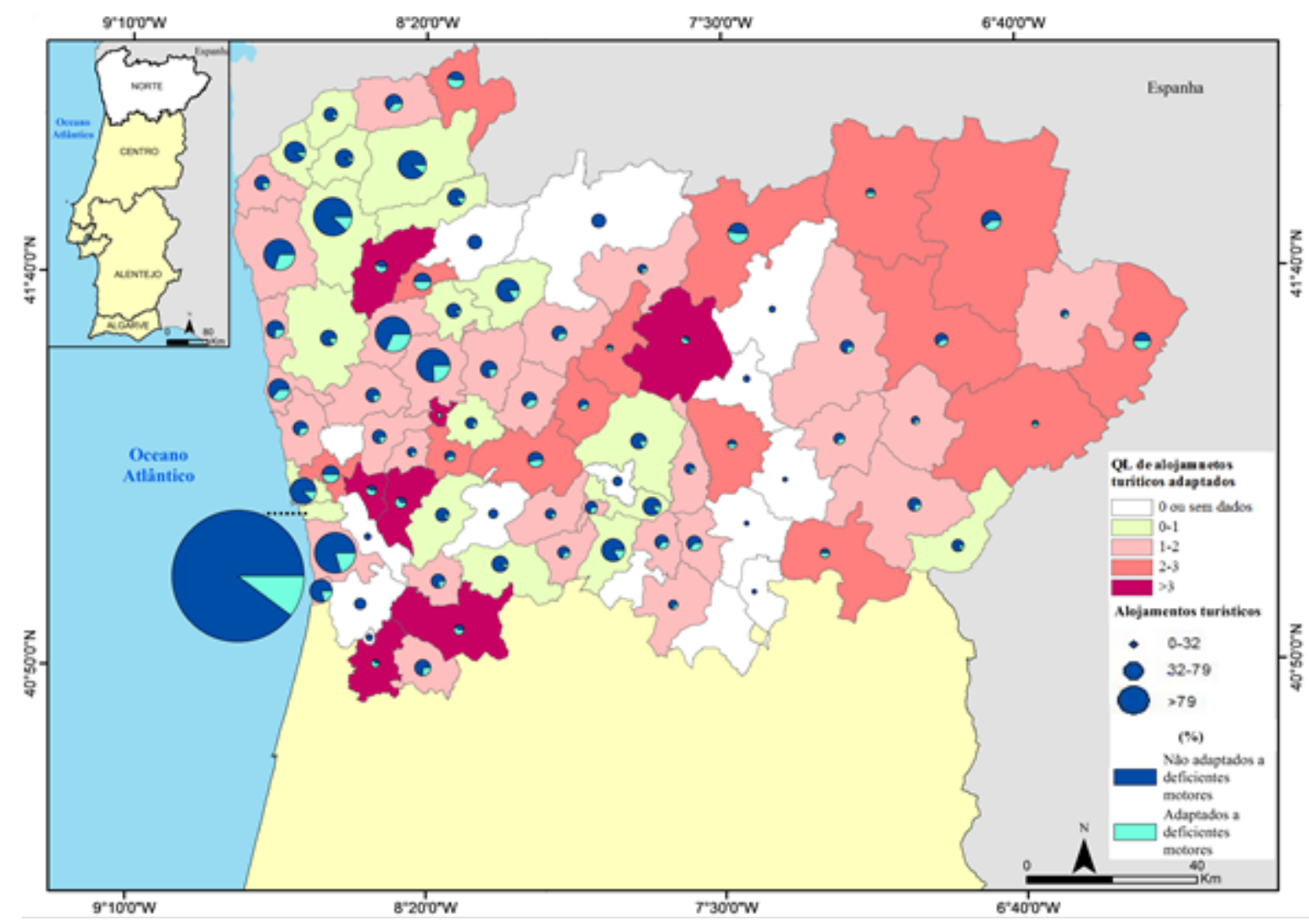

Figura 1: Alojamentos turísticos da Região Norte de Portugal e Quocientes de Localização de alojamentos turísticos com quartos adaptados a indivíduos com mobilidade reduzida, em 2016. Fonte: dados base de www.booking.com

Como seria expectável a maior concentração de alojamento turístico verifica-se no litoral e no Minho, com particular ênfase para o município do Porto, que nos últimos anos se tem afirmado como um dos principais destinos turísticos portugueses, tendo sido considerado em 2014, pela European Consumers Choise, o Melhor Destino Europeu. Este município concentra quase metade dos alojamentos turísticos da região (831), o que corresponde a 44,6\%, no entanto, apenas $85(10,2 \%)$ possui quartos adaptados. Uma proporção baixa que faz com que o município do Porto represente apenas cerca de $1 / 4$ dos alojamentos turísticos adaptados da região Norte.

Pode ainda constatar-se que três municípios não possuem alojamento turístico (AT) registado neste portal, 12 não têm alojamentos turísticos com quartos adaptados, 17 municípios possuem pelo menos metade dos alojamentos turísticos com quartos adaptados, sendo que os municípios que se destacam nesta proporção são aqueles que beneficiam de uma oferta de alojamentos turísticos mais reduzida, como é o caso do município de Vizela, que por só possuir uma unidade hoteleira e esta ter alojamento adaptado tem $100 \%$ do alojamento turístico com condições para acolher turistas com deficiência motora.

Com o cálculo do Quociente de Localização $^{3}$ dos alojamentos turísticos adaptados pretendeu-se perceber quais os municípios que se destacavam relativamente à média regional,

\footnotetext{
${ }^{3} \mathrm{QL} r \mathrm{rj}=\left(\mathrm{X}_{\mathrm{rj}} / \mathrm{X}_{\mathrm{r}}\right) /\left(\mathrm{X}_{\mathrm{pj}} / \mathrm{X}_{\mathrm{p}}\right)$ e $0 \leq \mathrm{QL} \leq \infty$ em que, $\mathrm{X}_{\mathrm{rj}}$ - no de AT adaptados no município; $\mathrm{X}_{\mathrm{r}}$ - № total de AT no município; $\mathrm{X}_{\mathrm{pj}}$ - № de AT adaptados na Região Norte; $X_{p}-$ No total de AT na Região Norte.
} 
tendo sido possível constatar que apesar do interior da Região Norte possuir em termos absolutos menor número de alojamentos turísticos uma parte importante deles possui quartos adaptados, contribuindo para que fiquem acima da média regional, sobretudo nas sub-regiões do Ave e Tâmega e a NW junto à fronteira com Espanha. No conjunto regional destacam-se oito municípios com quocientes de localização mais elevados: Vila Verde, Arouca, Valongo, Oliveira de Azeméis, Paredes, Vila Pouca de Aguiar e Vizela.

Focando a análise em Guimarães e, contextualizando-o muito sumariamente, este é um município pertencente à sub-região do Ave, constituído por 48 freguesias, contando, segundo estimativas do INE, com cerca de 155 mil habitantes em 2015, distribuídos por uma área total de $241,05 \mathrm{Km}^{2}$. A cidade de Guimarães possui uma malha urbana com uma área de $23,5 \mathrm{~km}$ que se difunde por 20 freguesias, ocupadas por cerca de 51 mil habitantes (Censos, 2011). Com boas acessibilidades a cidade de Guimarães encontra-se conectada por autoestrada às principais cidades vizinhas (Vila Nova de Famalicão - 30Km; Braga - $20 \mathrm{Km}$ e Porto - 57Km). O Centro Histórico de Guimarães, exemplo bem conservado de uma cidade medieval, foi classificado em 2001, pela UNESCO, Património da Humanidade, sendo considerada o Berço da Nação Portuguesa, local de nascimento do primeiro Rei de Portugal D. Afonso Henriques. Todos estes atributos têm contribuído para a inclusão da cidade em variados roteiros turísticos, revelando a importância deste estudo.

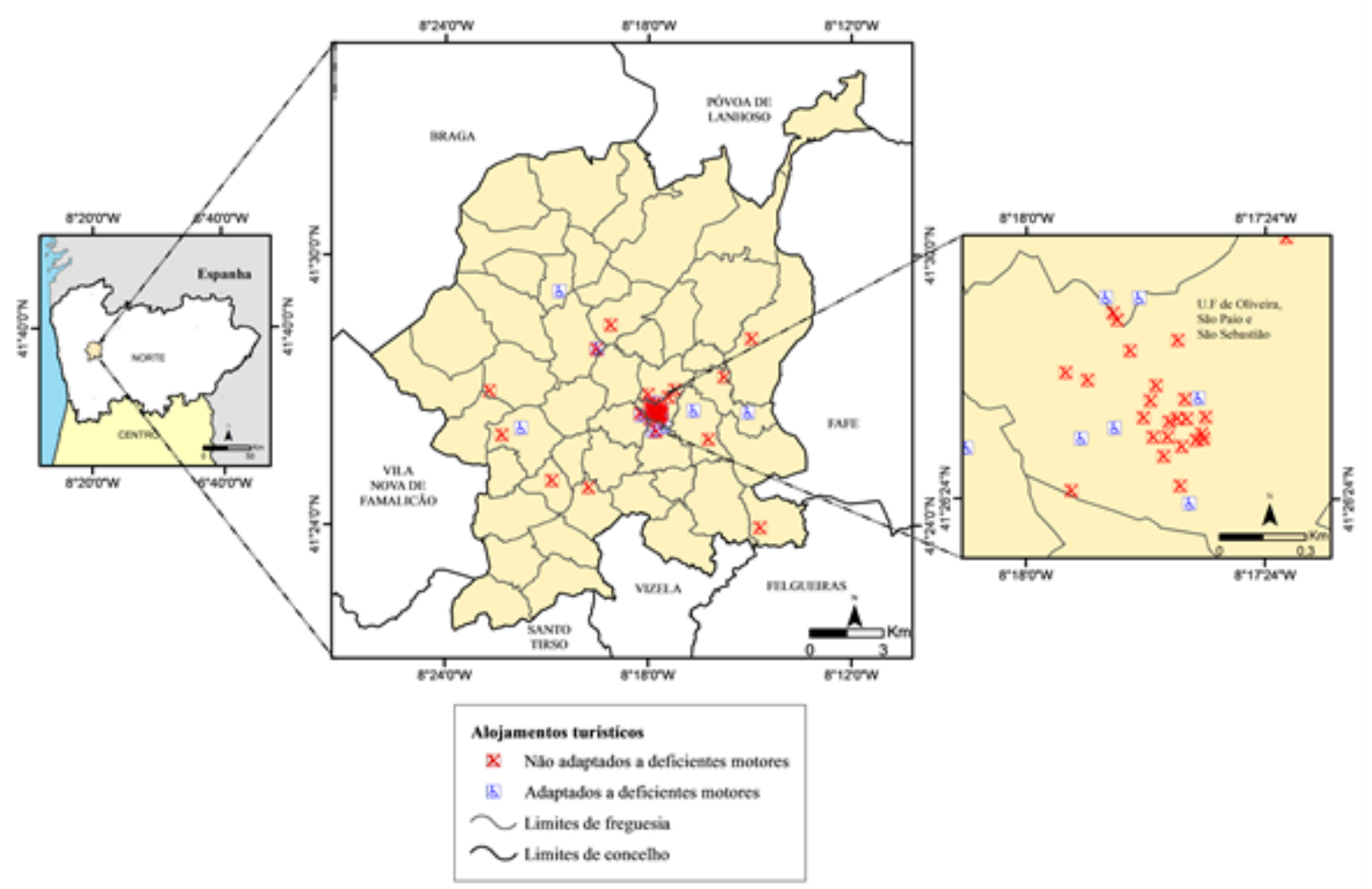

Figura 2: Alojamento turístico no município de Guimarães com quartos adaptados a indivíduos com mobilidade reduzida, em 2016. Fonte: dados base de www.booking.com

No que diz respeito à oferta de alojamento turístico, o concelho de Guimarães possui 53 hotéis registados no portal www.booking.com, sendo que 38 não estão adaptados para deficientes motores e apenas 15 (28,3\%) estão adaptados. A União de Freguesias de Oliveira, São Paio e São Sebastião, que corresponde ao centro histórico da cidade é onde se concentra o maior número de alojamentos turísticos, contudo apenas quatro possuem quartos adaptados. 0 
elevado número de alojamentos nesta freguesia deve-se ao surgimento, nos últimos anos de vários hostels e alojamento local que, por norma, não estão preparados para receber pessoas com deficiência motora (Figura 2). A avaliação da situação no quadro regional permite verificar que o município de Guimarães, ao nível da oferta de alojamento turístico com quartos adaptados, se encontra ligeiramente acima da média regional uma vez que regista um $Q L=1,33$.

Numa análise um pouco mais detalhada da oferta de alojamento turístico foi ainda possível verificar que o preço médio dos alojamentos turísticos com quartos adaptados a deficientes motores ronda os 65 euros. Os hotéis com mais estrelas e, por isso os mais dispendiosos, são os que melhores condições de acessibilidade oferecem. A oferta com preços mais acessíveis, por norma, não possui quartos adaptados à exceção da Pousada da Juventude que dispõe de dois quartos adaptados, com o custo médio de $25 €$ euros e o "Guimarães Living" com o custo médio de $23,5 €$.

Após a análise da oferta hoteleira pretendeu-se avaliar as condições de mobilidade e acessibilidade de um percurso turístico que permitisse a visita ao conjunto arquitetónico fundamental do Centro Histórico de Guimarães ${ }^{4}$. O percurso tem início no Castelo de Guimarães e termina na Plataforma das Artes (Figura 3), com uma extensão de aproximadamente 1414 metros. Para facilitar o estudo, o percurso foi subdividido em 6 troços (Troço A-B corresponde ao trajeto entre o Castelo de Guimarães e o Paço dos Duques de Bragança; Troço B-C Paço dos Duques de Bragança e a Rua Serpa Pinto (correspondendo ao Largo Martins Sarmento); Troço CD Rua Santa Maria; Troço D-E Largo de Santiago e da Oliveira; Troço E-F Rua da Rainha D. Maria II; Troço F-G Largo do Toural e Rua Paio Galvão, até à Plataforma das Artes.

A avaliação das condições de mobilidade ao longo do percurso contemplou a análise da orografia do trajeto através do cálculo de declives, o tipo e estado de conservação do piso, a existência de barreiras, a largura dos passeios, a existência de passadeiras rebaixadas e o tipo de tráfego das vias.

Tabela 1: Caracterização das condições de mobilidade do percurso por troços

\begin{tabular}{|c|c|c|c|c|c|c|}
\hline TROÇO & DECLIVE & PISO & $\begin{array}{l}\text { LARGURA } \\
\text { DO } \\
\text { PASSEIO }\end{array}$ & $\begin{array}{l}\text { PASSADEIRAS } \\
\text { REBAIXADAS }\end{array}$ & $\begin{array}{l}\text { TIPO DE } \\
\text { TRÁFEGO }\end{array}$ & BARREIRAS \\
\hline$A-B$ & $5-8$ & $\begin{array}{l}\text { Terra } \\
\text { batida }\end{array}$ & Inexistente & Inexistentes & Pedonal & Inexistentes \\
\hline$B-C$ & $>8$ & $\begin{array}{l}\text { Empedrado } \\
\text { Regular }\end{array}$ & Adequada & Sim & Misto & $\begin{array}{l}\text { Esplanadas } \\
\text { em frente ao } \\
\text { Paço dos } \\
\text { Duques }\end{array}$ \\
\hline$C-D$ & $5-8$ & Laje & Estreita & Não & Pedonal & Inexistentes \\
\hline$D-E$ & $0-5$ & $\begin{array}{l}\text { Empedrado } \\
\text { Irregular }\end{array}$ & Adequada & Não & Pedonal & Inexistentes \\
\hline$E-F$ & $0-5$ & $\begin{array}{l}\text { Empedrado } \\
\text { irregular e } \\
\text { Laje }\end{array}$ & $\begin{array}{l}\text { Alternância } \\
\text { de } \\
\text { dimensões }\end{array}$ & Não & Misto & $\begin{array}{l}\text { Floreiras } \\
\text { Candeeiros }\end{array}$ \\
\hline $\mathbf{F}-\mathbf{G}$ & $0-5$ & $\begin{array}{l}\text { Empedrado } \\
\text { Regular }\end{array}$ & Adequada & Sim & Misto & Inexistentes \\
\hline
\end{tabular}

\footnotetext{
${ }^{4}$ Sugerido pelo Posto de Turismo de Guimarães.
} 
Fonte: Levantamento de campo, 2016

O percurso selecionado apresenta vários problemas no que concerne às condições de mobilidade do espaço público para indivíduos com mobilidade reduzida (Tabela 1). Entre o Castelo e o Paço dos Duques o piso é irregular em terra batida e o declive é acentuado. O troço B - C correspondente ao Largo Martins Sarmento foi recentemente alvo de um Plano de Pormenor que alargou passeios, regularizou o piso e dotou toda a área de passadeiras rebaixadas, o maior problema que aqui se coloca é o declive acentuado. A Rua de Santa Maria tem um declive moderado, não tem passeios com dimensão adequada mas como é uma rua pedonal permite a circulação através da via. Nos Largos de Santiago e da Oliveira e Rua da Rainha os maiores problemas são a irregularidade do piso e a inexistência de passadeiras rebaixadas, a que acresce a dimensão inadequada dos passeios na rua da Rainha e a existência de algumas barreiras. $O$ troço entre o Largo do Toural e a Plataforma das Artes é o que apresenta as melhores condições, à semelhança do Largo Martins Sarmento, foi alvo de uma intervenção urbanística recente, em 2012, aquando da organização da Capital Europeia da Cultura, para além disso é uma área pouco declivosa, os passeios têm largura adequada e existem passadeiras rebaixadas.

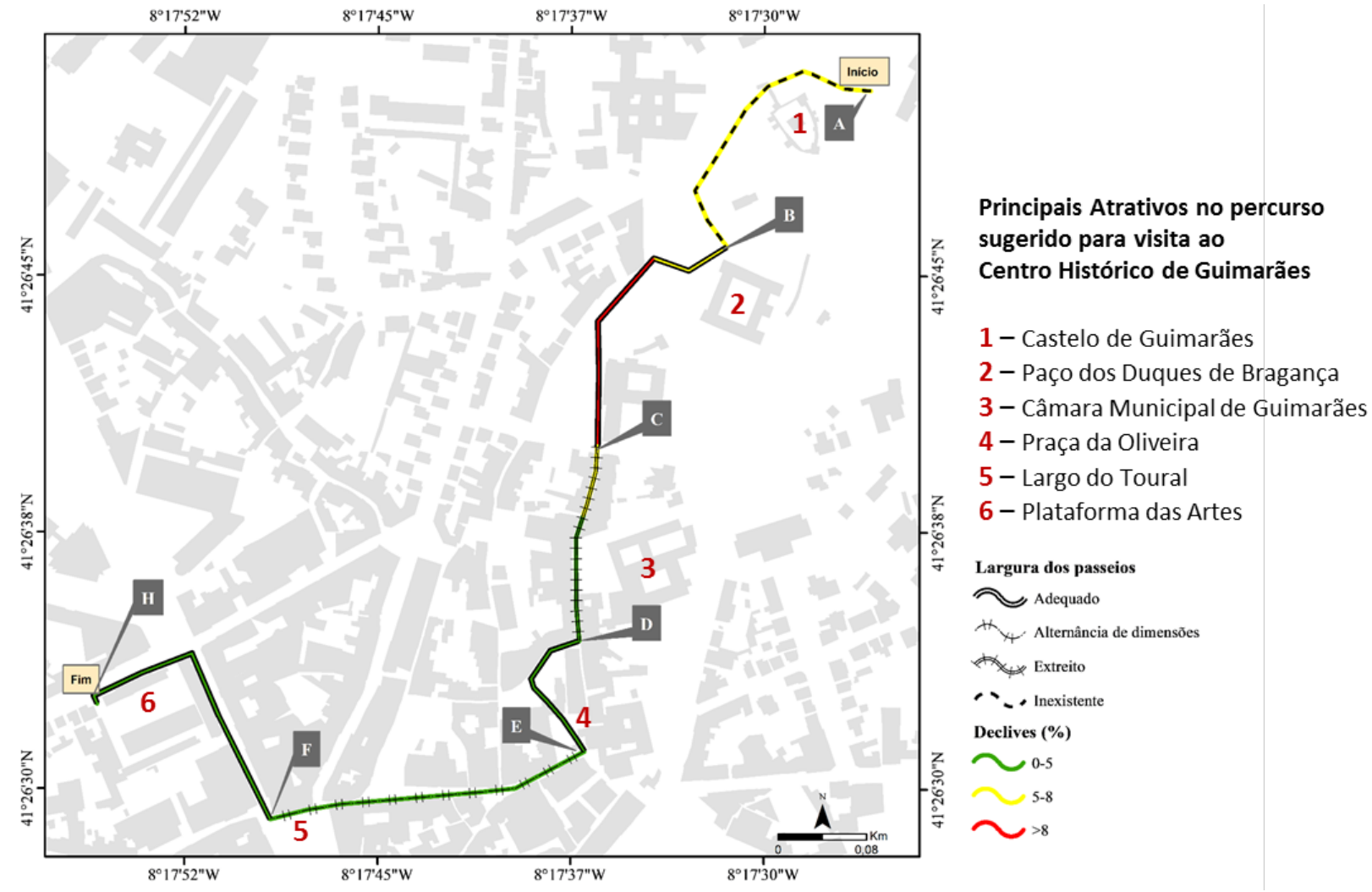

Figura 3: Avaliação do declive e largura dos passeios ao longo do percurso selecionado. Fonte: Elaboração própria

Como forma de avaliação conjunta das condições de mobilidade foi elaborada uma análise multicritério (Tabela 2) baseada nos seguintes parâmetros:

$\checkmark$ Declive: $>8 \%-1$; entre 8-5\% - 2; $<5 \%-3$

$\checkmark$ Tipo de Piso: Mau -1; Razoável - 2; Bom - 3 
$\checkmark$ Largura do Passeio: Inexistente - 1; Inadequado - 2; Adequado - 3

$\checkmark$ Passadeira rebaixada: Inexistente - 1; Existente - 2

$\checkmark$ Via: Com tráfego misto (peões e automóveis) - 1; Tráfego pedonal -2

$\checkmark$ Barreiras: Com Barreira - 1; Sem barreira - 2

Considerando que no conjunto dos critérios selecionados a importância de cada um deles para a mobilidade é diferenciada, tendo em atenção a área de estudo atribuiram-se fatores de ponderação que pretendem afinar esta avaliação. Assim, o declive vale uma ponderação '4'; o tipo de piso ' 3 '; largura do passeio '3'; existência de passadeiras rebaixadas '3'; tráfego das vias ' 1 ' e existência de barreiras ' 2 '.

Tabela 2: Análise multicritério para a avaliação das condições de mobilidade por troços do percurso

\begin{tabular}{|c|c|c|c|c|c|c|c|}
\hline Troço & Declive & Piso & $\begin{array}{l}\text { Largura } \\
\text { do } \\
\text { passeio }\end{array}$ & $\begin{array}{l}\text { Passa- } \\
\text { deira }\end{array}$ & Trafego & $\begin{array}{l}\text { Barreiras } \\
\text { arquitetónicas }\end{array}$ & $\begin{array}{l}\text { Avaliação } \\
\text { Final }\end{array}$ \\
\hline$A-B$ & $2 \times 4$ & $2 \times 3$ & $1 \times 3$ & $1 \times 3$ & $2 \times 1$ & $1 \times 2$ & 24 \\
\hline$B-C$ & $1 \times 4$ & $3 \times 3$ & $3 \times 3$ & $2 \times 3$ & $1 \times 1$ & $2 \times 2$ & 33 \\
\hline$C-D$ & $2 \times 4$ & $3 \times 3$ & $2 \times 3$ & $1 \times 3$ & $2 \times 1$ & $2 \times 2$ & 32 \\
\hline$D-E$ & $3 \times 4$ & $1 \times 3$ & $2 \times 3$ & $1 \times 3$ & $2 \times 1$ & $2 \times 2$ & 30 \\
\hline$E-F$ & $3 \times 4$ & $1 \times 3$ & $2 \times 3$ & $1 \times 3$ & $1 \times 1$ & $1 \times 2$ & 27 \\
\hline$F-G$ & $3 \times 4$ & $3 \times 3$ & $3 \times 3$ & $2 \times 3$ & $1 \times 1$ & $2 \times 2$ & 41 \\
\hline
\end{tabular}

Fonte: Elaboração própria

Em suma, o percurso é muito difícil de percorrer por pessoas com mobilidade reduzida nos troços A-B e E-F mas por razões distintas, o primeiro essencialmente por causa do piso e do declive, o segundo por uma conjugação de problemas: o subdimensionamento dos passeios conjugado com a inexistência de passadeiras e a existência de tráfego automóvel. O troço que proporciona uma mobilidade mais fácil é o último entre o Largo do Toural e a Plataforma das Artes, o único que consideramos passível de ser efetuado autonomamente, sem necessidade de acompanhante, sendo que todos os outros requerem acompanhamento e ajuda. Convém ainda referir que o troço B-C apesar de ter sofrido uma intervenção urbanística que teve em atenção as pessoas com mobilidade reduzida, nomeadamente com a adequação da dimensão dos passeios, do tipo de piso e do rebaixamento de passadeiras (o que explica o seu posicionamento nesta avaliação) a orografia do terreno não permite efetuar o percurso autonomamente.

Efetuada a avaliação das condicionantes à mobilidade debruçámo-nos sobre as questões da acessibilidade, em que para esta análise se procedeu ao levantamento dos monumentos, edifícios públicos, comércio e serviços passíveis de serem utilizados pelos turistas e aferimos as suas condições para acolher pessoas com mobilidade reduzida. Neste sentido foi verificada a possibilidade de acesso e circulação (existência de degraus/elevador/rampas) e a existência de casas de banho adaptadas (Figura 4). Para isso recorreu-se ao contributo de um cidadão com mobilidade reduzida que testou o percurso selecionado, percorrendo-o na sua totalidade com o intuito de avaliar o grau de acessibilidade aos espaços interiores que ao longo desse trajeto o turista pode visitar ou usufruir 


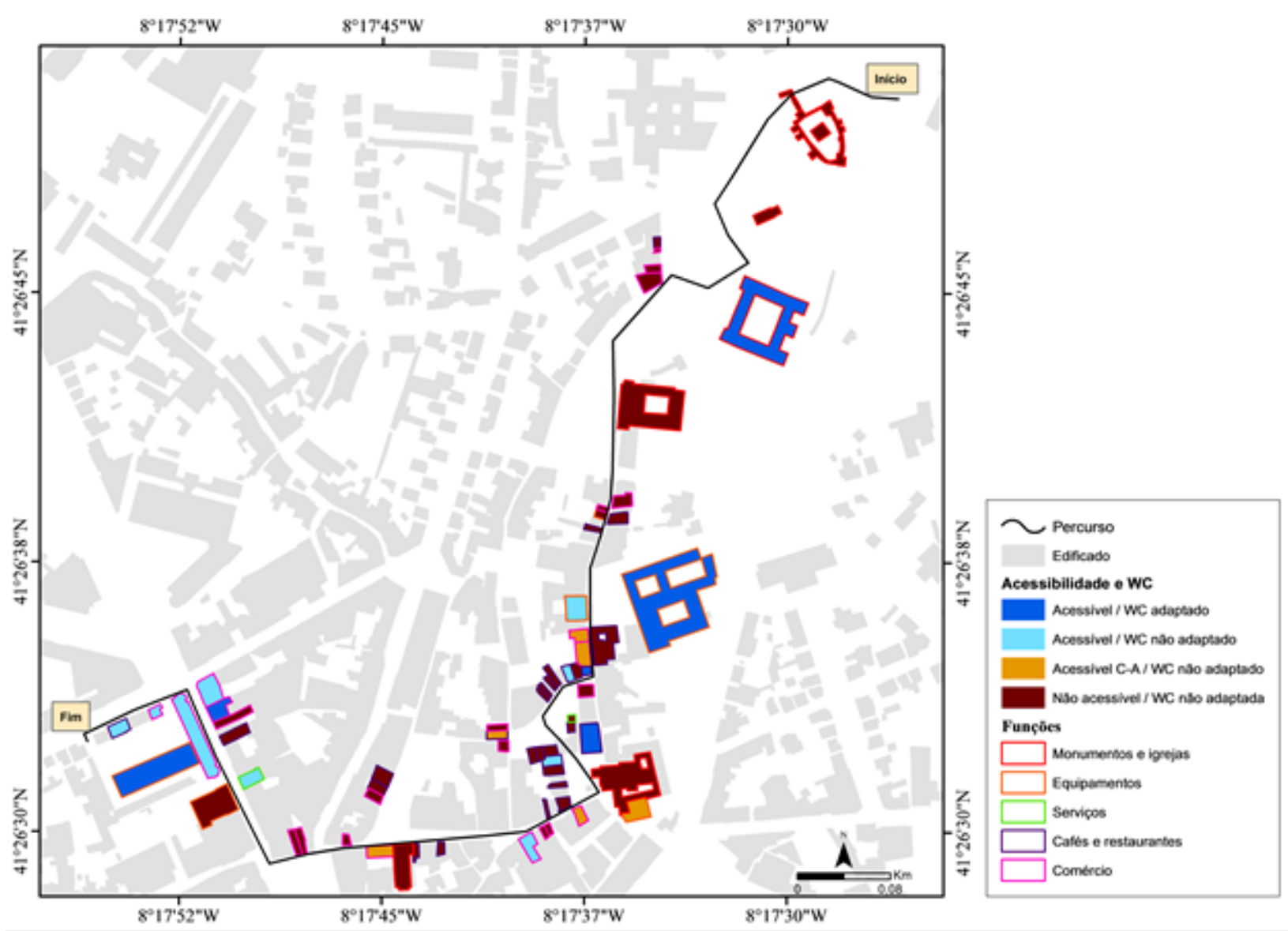

Figura 4: Acessibilidade e levantamento funcional ao longo do percurso. Fonte: Elaboração própria

Ao longo do percurso selecionado, somente seis espaços abertos ao público (num total de 69) se podem considerar acessíveis, uma vez que possuem acessos adequados e WC adaptados: Paço dos Duques; Câmara Municipal de Guimarães; Posto de Turismo; um restaurante que faz parte do Hotel da Oliveira; um supermercado e a Plataforma das Artes (Figura 5). Este levantamento deixa patente que apesar da legislação portuguesa exigir a adaptação dos edifícios públicos, tornando-os acessíveis, ainda nos encontramos algo afastados deste objetivo. Apesar de compreendermos que para alguns espaços a adaptação é muito difícil ou quase impossível (e.g. Castelo de Guimarães ou algumas igrejas espalhadas pela cidade), noutros edifícios é incompreensível que tal aconteça, nomeadamente no que respeita à inexistência de WC adaptados.

No trajeto encontrámos nove espaços (na maioria comércio e serviços) e a Biblioteca Municipal Raul Brandão que proporcionam condições de acesso mas não possuem WC adaptado, e cinco espaços permitem o acesso com alguma ajuda mas também não dispõem de WC adaptado, destacando destes, o Museu Alberto Sampaio.

Com a análise efetuada foi possível ainda verificar que uma parte muito significativa (44) dos estabelecimentos comerciais considerados (essencialmente lojas de artesanato, cafés/bares e restaurantes) não têm acesso a cadeiras de rodas. A maioria possui degraus na entrada e/ou no interior dos estabelecimentos, nalguns a circulação é igualmente difícil e a grande maioria dos restaurantes e cafés não têm casa de banho adaptada.

Assim, em termos de turismo acessível o Centro Histórico de Guimarães depara-se com algumas fragilidades que importa combater, não apenas na circulação nos espaços exteriores 
mas no acesso ao interior de espaços (público ou semi-públicos). Aceitando que nem todos os estabelecimentos serão passíveis de ser adaptados devido à exiguidade do espaço (muitos dos restaurantes do centro histórico são espaços relativamente pequenos, onde a instalação de WC adaptado é difícil), todavia outros têm essa possibilidade, faltando apenas a iniciativa dos proprietários e a exigência das autoridades públicas. Mais grave ainda é a existência de um sanitário público, no Largo Santiago, que igualmente não se encontra adaptado a pessoas com mobilidade reduzida e não possui WC adaptado.

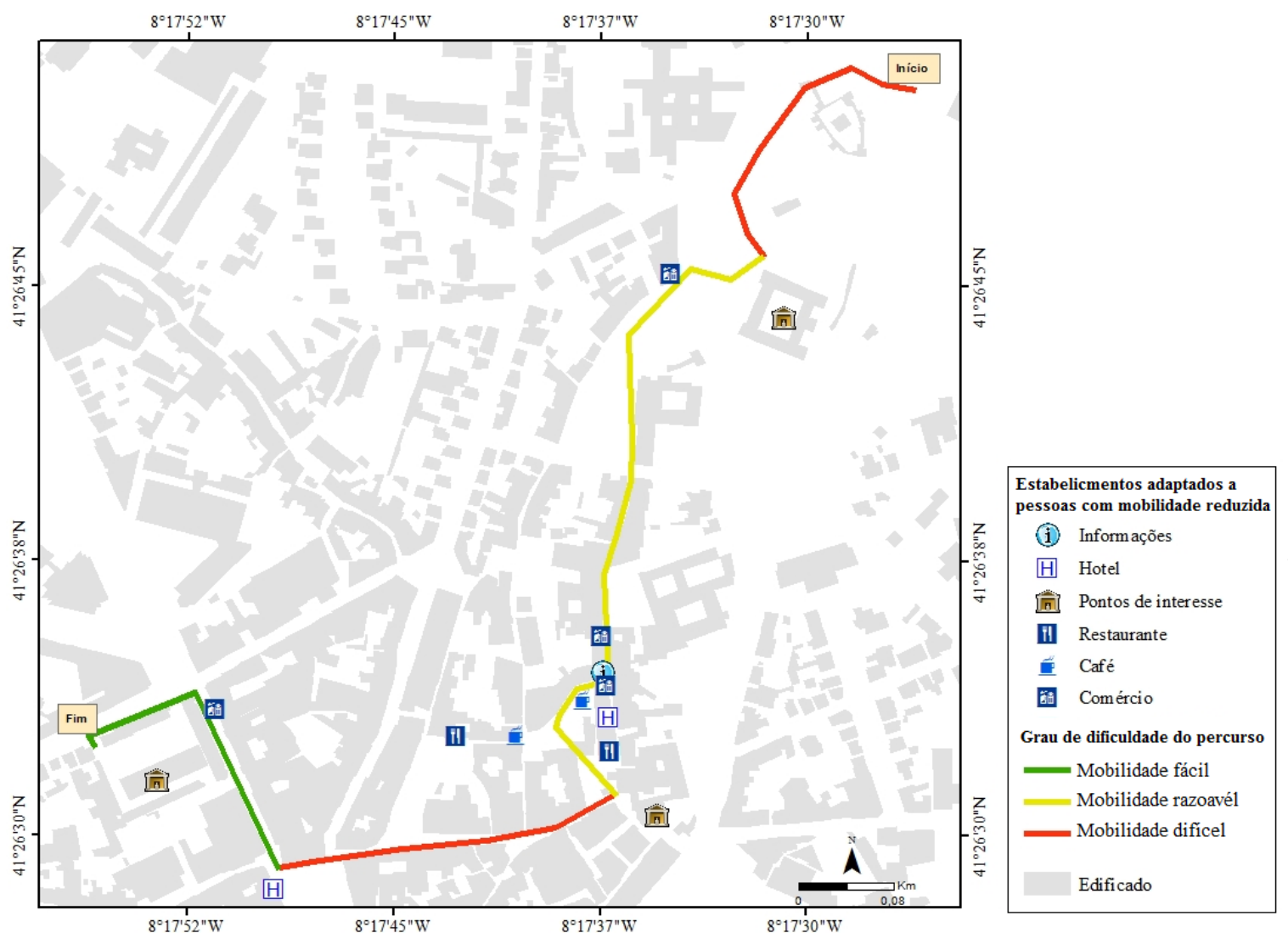

Figura 5: Síntese das condições de mobilidade e acessibilidade do percurso Fonte: Elaboração própria

Em termos de acessibilidade podemos então considerar que muito pode e deve ser feito, não só no acesso aos estabelecimentos mas sobretudo na construção de WC adaptados.

Para finalizar este estudo apresentamos uma planta síntese das condições de mobilidade e acessibilidade do percurso em análise (Figura 5). A disponibilização deste tipo de materiais que podem, na atualidade, ser desenvolvidos com o recurso a aplicações eletrónicas e difundidos muito facilmente, possibilita uma forma prática e simples de fornecer informação fundamental a visitantes e turistas com mobilidade reduzida permitindo um planeamento e o usufruto da experiência que é visitar o Centro Histórico de Guimarães mais enriquecedor.

\section{CONCLUSÃo}

O estudo das condições que um percurso pelo Centro Histórico de Guimarães oferece a um turista com mobilidade reduzida, revelou que existe ainda um conjunto de debilidades que urge resolver por forma a tornar o percurso acessível a todos. Foram detetados problemas a vários níveis que implicam a necessidade de atuar junto dos diversos níveis de governança 
(autoridades e os atores locais) de Guimarães para adequar a oferta turística e a cidade a todos os públicos.

Com a análise efetuada foi possível perceber que a visita ao Centro Histórico de Guimarães para visitantes ou turistas com mobilidade reduzida é algo complicada. Convém no entanto ressalvar que se têm registado melhorias e uma preocupação crescente com esta problemática, evidente na incorporação dos princípios de desenho universal nas intervenções urbanas efetuadas mais recentemente (e.g. Largo Martins Sarmento, Largo do Toural, Plataforma das Artes) e na eliminação de barreiras, atualmente já pouco presentes ao longo do percurso selecionado. Contudo, subsistem igualmente problemas, alguns de fácil resolução e outros quase impossíveis de solucionar.

No que respeita à oferta de alojamento turístico, a preocupação em elevar a disponibilidade de quartos adaptados é uma evidência, sendo que a maior lacuna se regista no segmento do alojamento menos dispendioso.

Ao nível da mobilidade o problema mais difícil de resolver prende-se com a orografia do terreno, uma vez que estamos perante uma cidade que apresenta algumas áreas com declives acentuados, o que impossibilita a mobilidade autónoma. Outros problemas são de muito fácil resolução, só necessitando da vontade das entidades públicas, nomeadamente a melhoria do piso e a construção de passadeiras rebaixadas. A alteração destas duas condicionantes facilitaria em muito as condições de mobilidade no Centro Histórico de Guimarães.

Por fim, no que respeita à acessibilidade aos diversos edifícios os problemas maiores relacionam-se com a existência de degraus, algo de muito fácil resolução através da construção de rampas (definitivas), ou a adoção de formas mais flexíveis (rampas amovíveis). Outro grande problema é a inexistências de casas de banho adaptadas na maioria dos estabelecimentos de restauração, e embora para alguns seja difícil solucionar este constrangimento devido à exiguidade do espaço, para outros seria relativamente fácil a criação de WC's adaptados. Neste sentido seria fundamental que a autarquia renovasse e adaptasse as instalações sanitárias públicas e promovesse uma campanha de sensibilização junto dos comerciantes.

Resulta evidente que apesar de progressos notórios ainda há muito caminho a percorrer se se pretender consubstanciar Guimarães como um destino turístico acessível. Caminho que exige vontade e articulação entre os diversos organismos e entidades, pois como afirmam Buhalis, Darcy e Ambrose,

"Successful businesses and destinations depend on building well-functioning networks and
partnerships (...) The chain must be developed in each of its links, e.g. transport, attractions,
accommodation, and the must be reliable connections between all links if the customer is to
receive adequate services throughout the journey (...) Accessible hotels, restaurants,
museums and other visitor attractions must not be isolated 'oases of accessibility' within
otherwise inaccessible landscapes; they must be physically joined up by accessible routes and
transport systems" (Buhalis, Darcy e Ambrose, 2012: p.6).

Mas acima de tudo, a melhoria das condições de mobilidade e acessibilidade dos espaços é uma afirmação de cidadania e uma oportunidade para inovar, promover a qualidade e a sustentabilidade, beneficiando todos e envolvendo todos, construindo assim, territórios cada vez mais inclusivos. 


\section{AGRADECIMENTOS}

Os autores agradecem ao Duarte Nunes e Ana Laura Costa, alunos do 3 ano da Licenciatura em Geografia e Planeamento da Universidade do Minho, pela colaboração no trabalho de campo.

\section{REFERÊNCIAS}

Abley, S. (2005). Walkability Scoping Paper.

http://www.levelofservice.com/walkability-research.pdf. Consultado em 12 de Julho de 2016.

Anacleto, C. (2014). Turismo acessível: criação de um circuito turístico para a população com deficiência visual, na cidade de Braga. (Dissertação de Mestrado). Braga: Universidade do Minho.

APA (2010). Manual de boas práticas para uma mobilidade sustentável. Volume II. Lisboa: Agência Portuguesa do Ambiente.

Buhalis, D. \& Costa, C. (Eds.) (2005). Tourism Manegement Dynamics: Trends, Management and Tools (Tourism Futures), London: Routledge.

Buhalis, D., Darcy, S. \& Ambrose, I. (2012). Best Practice in Accessible Tourism: Inclusion, Disability, Ageing Population and Tourism. Exeter: Short Run Pres.

Buhalis, D.; Eichhorn, V.; Michopoulou, E. \& Miller, O. (2005). Accessibility Market and Stakeholder Analysis. Surrey: University of Surrey \& OSSATE - One-Stop-Shop for Accessible Tourism in Europe.

Carvalho, I. (2015). O Turismo Acessível: estratégias de adaptação de uma cidade. (Tese de Doutoramento). Lisboa: Instituto Geografia e Ordenamento do Territorio - Universidade de Lisboa.

CML (2013). Plano de Acessibilidade Pedonal de Lisboa. 5 Volumes. Lisboa: Câmara Municipal de Lisboa.

DECO (2011). Acesso Condicionado. Revista Proteste, 321, pp. 12 - 17.

Domingues, C. \& Carvalho, P. (2013). Acessibilidade e Turismo na Cidade de Coimbra. Turismo y Desarrollo Local, 14. 2013

EUCAN (2003). European Concept for Accessibility. Luxembourg: European Concept for Accessibility Network.

http://acessibilidade.cm-lisboa.pt/index.php?id=175. Consultado a 12 de Julho 2016.

Gutiérrez, J.; Condeço, A. \& Martín, J. M. (2007). Using accessibility indicators and GIS to assess and monetarize spatial spillovers of transport infrastructure, 47th Congress of European Regional Science Association, Paris.

IMTT (2003). Rede Pedonal. Princípios de planeamento e desenho. Lisboa: Instituto da Mobilidade e dos Transportes Terrestres.

INE (2011). Recenseamento Geral da População e Habitação. Lisboa: Instituto Nacional de Estatística.

Ingram, D. (1971). The concept of accessibility: A search for an operational form. Reg. Studies, 5, 101-107.

INI (2010). Turismo Acessível em Portugal. Lei, oportunidades económicas, informação. Col. 
Informar (7). Lisboa: Instituto Nacional para a Integração.

Litman, T. (2007). Measured: Developing Indicators for Comprehensive and Sustainable Transport Planning. Victoria: Victoria Transport Policy Institute.

Metz, D (2000). Mobility of older people and their quality of life. Transport Policy, 7 (2), 149-152.

OMS (2011). Relatório Mundial sobre a Deficiência. São Paulo: Organização Mundial da Saúde.

OMT (1999). Código Munial de Ética do Turismo. Madrid: Organização Mundial do Turismo.

OMT (2009). Estatutos de la Organización Mundial del Turismo. Madrid: Organização Mundial do Turismo.

Perez, D. \& Velasco, D. (2003). Turismo Accesible. Madrid: Comité Español de Representantes de Personas com Discapacidad.

Ribeiro, V. (2014). Exclusão social - um fenómeno invisível. Faro: Silabas \& Desafios.

SNRIPD (2007). Guia, Acessibilidade e Mobilidade para todos. Apontamentos para uma melhor interpretação do DL 163/2006 de 8 de Agosto. Lisboa: Secretariado Nacional de Reabilitação e Integração para as Pessoas com Deficiência.

Teles, P. (2014). A cidade das (i)mobilidades: Manual técnico de acessibilidades e mobilidades para todos. Porto: MPT. 